\title{
A view from the edge: A first-time attendee's perspective
}

Since joining the eld, I have heard that the ACRL National Conference is a great professional development opportunity. Many colleagues told me it is the best conference they attend.This year I had the opportunity to go, as a presenter, thanks to the generosity of my institution and an ACRL scholarship.

Having attended ALA Annual Conference, I had an idea of what to expect, but was not sure how a divisional conference might be different. Luckily, the rst thing on my schedule was to attend the First-Time Attendees Orientation. We learned to expect programs targeting academic libraries, rather than meetings. The Innovations Committee shared the conference $\mathrm{s}$ Web 2.0 tags and tools. We learned how the conference would be green. ACRL leaders explained the organization and how to get involved.

I was surprised by the size of the venue and the large number of people in attendance. Programs were much larger than I expected.Many of the rooms held hundreds of people. Most time slots offered several interesting programs to choose from.Luckily, the virtual conference provides information for the sessions, so attendees can still get the information for sessions they couldn $t$ attend. It was amazing to be at a conference where every session approached librarianship from the academic perspective. Even those sessions not obviously tied to my own work gave me a better perspective of the larger eld of academic librarianship.

I attend this conference, in part, because I was on Steven Bell, John Shank, and Brian Mathew s panel, Mapping Your Path to the Mountaintop: Planning Where You Want To Be In Your Career. It was a great panel of people to work with: we incorporated multimedia and encouraged the audience to share their own thoughts. We had an engaged group, and participation in the panel was very rewarding.

Roundtables were all held in one large room. Each table discussed a prede ned topic.This was a nice opportunity to talk in small groups about speci c areas of interest. Lauren Ray and I hosted a table on collaborative development of online library instruction tools. I have been pleasantly surprised that we have continued the discussion through e-mail since returning home.

There were a number of other events in addition to the programs and roundtables. The Chair s Reception, for those presenting at the conference, was held 75 oors up at the Columbia Tower Club, with great food and an amazing view.The keynote speakers were fabulous, and I was always able to get a great seat.The All Conference Reception was held at the Experience the Music Project and Science Fiction Museum, with amazing desserts and a little something for everyone.

One of the things that helped me feel most in the loop at this large and new event was the informal communication that took place online. ACRLs tag, acrl2009, made it easy to nd information about the conference. Twitter and Facebook allowed me to keep up with other sessions, nd people I knew, and know what people were thinking of the conference as it happened.

I was most impressed with how, for a large conference, everything was tied together. Most people I spoke with attended all the keynotes and went to the All Conference Reception, leading to a shared conference experience. I was also impressed with how the conference pulled together online communication about the conference from Twitter, Flickr, and blogs, into a slideshow at the nal keynote. It was fun to see friends and events we had all attended on the big screens, and to know that other attendees had provided all the content.

ACRL was an enjoyable and informative conference, and I feel fortunate to have attended and participated in a presentation. The next ACRL National Conference will be in 2011 in Philadelphia.I look forward to getting a chance to participate again! Lauren Pressley, Wake Forest University, pressllm@ wfu.edu $n$ 